\title{
Editorial
}

\section{Formación del odontólogo en la época actual}

Cecilia María Martínez Delgado 1,a

${ }^{1}$ Universidad CES, Medellín, Colombia.

a Odontóloga Epidemióloga, Magíster en Dirección Universitaria.

\section{Correspondencia:}

Cecilia María Martínez Delgado

Correo electrónico: cmartinezd@ces.edu.co

Calle 10A \# 22-04 Barrio El Poblado, Bloque C, tercer piso.

Facultad de Odontología, Universidad CES.

Recibido: $17 / 06 / 19$

Aceptado: 09/09/19

Publicado: $27 / 11 / 19$

\section{Training of the dentist in the current era}

No es una frase vacía decir que la salud bucal está íntimamente ligada a la salud general o sistémica y tampoco lo es cuando decimos que sin salud bucal no hay buena salud general. La boca es un componente esencial de los seres vivos y tiene múltiples funciones: supervivencia, reconocimiento del mundo, comunicación y expresión de nuestras ideas, afectividad y erotismo, y estética, por mencionar algunos.

Además de la importancia ya expresada sobre la boca, $y$, teniendo en cuenta que nos ocupamos del componente bucal de la salud, nos debemos hacer una pregunta central: ¿Qué tipo de odontólogo, en esta época histórica, en nuestras culturas, en las coyunturas políticas para los países latinoamericanos, se espera formar, en consonancia con las necesidades sentidas y atendidas de la población?

La formación de odontólogos es parte del quehacer universitario, un quehacer definido por Cortés Rodas (2015, p.14) como “... la formación y preparación de personas para el ejercicio de las profesiones públicas y para el desarrollo de las capacidades investigativas... la base sobre la cual la sociedad y el Estado pueden dar lugar a la más clara conciencia de la época" ${ }^{1}$. Quiere decir entonces que es necesario reflexionar sobre la conciencia de la época para la Odontología. ¿YY cuál es esa conciencia de época?
Actualmente, es bien cierto que hay una tendencia mundial a la disminución de los índices COP-D (cariados, obturados, perdidos por diente); es decir, de alguna manera la caries dental presenta un descenso general, no así en determinados grupos poblacionales ${ }^{2}$, principalmente los menores de cinco años. Aunque la Federación Dental Internacional (FDI, 2015) revela que no hay datos estandarizados ni confiables del comportamiento epidemiológico de tal patología, sí manifiesta la debilidad de los sistemas sanitarios para tratarla oportunamente y la falta de información epidemiológica que "restringe el desarrollo de enfoques apropiados para reducir la carga de la enfermedad" ${ }^{3}$.

Las patologías bucodentales representan una importante carga de morbilidad y de complicaciones, sin embargo, tampoco hay demostración fehaciente del costo-efectividad de los tratamientos tempranos. Son escasos los estudios que demuestran que es más costo-efectivo el monitoreo y vigilancia epidemiológica que el tratamiento, por oportuno que éste sea. Si nos acercamos a las enfermedades periodontales, el horizonte es sombrío al relacionarlas con los indicadores de disminución de pérdida dental por estas causas, tampoco hay estudios globales sobre el tema de edentulismo por causa de las enfermedades periodontales, se sabe, pero no se logra demostrar con datos y hechos. 
También ha tomado fuerza el argumento de la relación entre enfermedades crónicas (NCD's) y enfermedades periodontales. Autores como Masi, D'Aiuto \& Deanfield (2019) ${ }^{4}$, Morales y cols (2016) ${ }^{5}$, Petersen \& Ogawa $(2012)^{6}$ sustentan dicha relación y en ese sentido, es importante orientar los esfuerzos hacia la comprensión que deben lograr quienes toman las decisiones políticas sobre salud bucal ${ }^{7}$, para que se pase a la acción en pro del mantenimiento de la salud bucal y general.

Todas estas ideas se relacionan con la formación del odontólogo, o profesional de la salud bucal, o médico de la boca. Durante muchos años se ha reclamado el liderazgo de la profesión para intervenir en diversos ámbitos relacionados con la salud y con la salud bucodental, de hecho hoy existen cátedras de liderazgo, de emprendimiento; en fin, una serie de contenidos desarticulados que se adicionan al plan de estudios sin que logremos posicionarnos más allá del ámbito estético; tan grave es la situación que, por ejemplo en Colombia, muchas Empresas Promotoras de Salud (EPS) exigen cursos de educación continua (diplomados) en estética. Y, los odontólogos, sin valorar las consecuencias que estos procedimientos pueden generar, acreditan dichos cursos así sean de dudosa calidad, con tal de certificarse para acceder a un puesto de trabajo.

Hay demanda por lo estético, por cuanto no hay conciencia de salud sino de estereotipos y, precisamente para alcanzarlos, se recurre a procedimientos que pueden implicar demandas penales por la conexión ético-legal que existe entre las prácticas inapropiadas y el daño a la salud. Por tanto, si el interés es promover la salud, se debe actuar en consecuencia, precisamente cuidándonos de malas prácticas que generan daños irreversibles a quienes requieren nuestros servicios. En ese sentido, el deber del profesional odontológico es educar de manera clara y ante todo ética, a quienes acuden en nuestra búsqueda, explicando ante todo los riesgos que pueden presentarse por cualquier práctica que comprometa el todo del sistema estomatognático.

Es cierto que estudiamos una profesión para la vida, en términos de lo que significa la educación superior: la formación en y para la alta inteligencia, sin olvidar que necesitamos posicionarnos en un mercado laboral que nos permita vivir con holgura económica, mercado por demás saturado dada la cantidad de egresados en todos los países, con muy poco margen de maniobrabilidad debido a las políticas en cuanto a prestación de servicios de salud bucal que siguen considerándose estéticos y no como consecuencia del proceso salud - enfermedad - trabajo.

Mientras la misma profesión no se dé cuenta de que debe intervenir más en las causas de enfermar y morir, y, las universidades eduquen a los estudiantes y a sus profesores para este razonamiento, será imposible que nos tomen en cuenta de manera seria y profunda. No pasamos de oír a quienes administran los pocos o muchos recursos, que gastamos mucho dinero en la atención de los usuarios, y por ello, todos los días los planes de beneficio odontológico que ofrecen las aseguradoras sufren más recortes y mayor aplazamiento de las intervenciones necesarias para los pacientes.

La conciencia de la nueva época para formadores y prestadores, es la investigación en tres campos principales:

1. Cuál es el marco teórico o fundamentación teórica y disciplinar que sustenta a los programas de odontología, particularmente en América Latina?

2. ¿Qué estudios recientes de contexto disciplinar existen, que permitan validar la pertinencia de los programas actualmente?

3. ¿Qué aportes significativos le hacen los programas donde operan o funcionan, a la región y al país?

Aunque suene a discurso retrógrado, no es investigación nanotecnológica, de materiales o de procedimientos, de lo que llamamos de punta, lo que necesitamos para "situarnos" a la par de los países desarrollados, que es lo que se pregona permanentemente y que vemos todos los días como un horizonte más lejano, por la escasez de recursos destinados al desarrollo de nuevos conocimientos.

La conciencia de la nueva época debe responder principalmente al estado del arte de la profesión actualmente, pensando en los futuros egresados, cada vez con menores ingresos y con mayores inestabilidades en sus contratos, transgrediendo el derecho a un empleo digno y a un futuro económico seguro.

\section{Referencias bibliográficas}

1. Cortés Rodas F. La ruta social de la razón en la universidad. Democracia y deliberación. Eidos. 2015;23:13-36.

2. Petersen PE, Ogawa H. Prevention of dental caries through the use of fluoride - the WHO approach [editorial]. Community Dental Health. 2016(33):66-68.

3. World Dental Federation (FDI). A new definition for oral health developed by the FDI World Dental Federation opens the door to a universal definition of oral health. Int Dent J. 2016;66:322-324. DOI: 10.1111/ idj.12294.

4. Masi S, D'Aiuto F, Deanfield J. Cardiovascular Prevention Starts From Your Mouth. Eur Heart J. 2019;40(14):1146-1148. DOI: 10.1093/eurheartj/ ehz060.

5. Morales A, Bravo J, Baeza M, Werlinger F, Gamonal J. Las enfermedades periodontales como enfermedades crónicas no transmisibles: Cambios en los paradigmas. Rev Clínica Periodoncia Implantol Rehabil Oral. 2016;9(2):203-7.

6. Petersen PE, Ogawa H. The global burden of periodontal disease: towards integration with chronic disease prevention and control. Periodontol 2000. 2012;60(1):15-39.

7. Sheiham A, Williams DM, Weyant RJ, Glick M, Naidoo S, Eiselé JL, et al. Billions with oral disease: A global health crisis--a call to action. J Am Dent Assoc. 2015;146(12):861-4. DOI: 10.1016/j. adaj.2015.09.019. 